\title{
EL COMERCIO ALIMENTICIO EN ARGENTINA 2001-2006: ANÁLISIS TERRITORIAL DEL SECTOR SUPERMERCADISTA.
}

\section{THE NUTRITIOUS TRADE IN ARGENTINEAN 2001-2006: TERRITORIAL ANALYSIS OF THE SECTOR OF SUPERMARKETS.}

Lic. Josefina, Di Nucci

Becaria CONICET. Centro de Investigaciones Geográficas (CIG). FCH. UNCPBA. Tandil. Argentina Mgter. Santiago Linares

Becario CONICET. Centro de Investigaciones Geográficas (CIG). FCH. UNCPBA. Tandil. Argentina

En Revista Geográfica Digital. Instituto de Geografía, Facultad de Humanidades. UNNE. ISSN 1668-5180.

Año 6. № 9. Enero -Junio 2008.

http://hum.unne.edu.ar/revistas/geoweb/default.htm

\section{Resumen}

A partir del año 2001, la crisis y sus consecuencias se hicieron sentir en el comercio alimenticio y si bien es claro, que el supermercadismo y la concentración económica de los grupos de distribución en Argentina no se revirtió, se evidencia desde ese año y con mayor énfasis después de la devaluación (2002) un estancamiento y posterior decrecimiento del sector supermercadista argentino, para volver a crecer a partir del año 2005. Se presenta en este trabajo, un análisis profundo de la gran distribución (GD) en Argentina, en el periodo 2001- 2006, a través de los datos oficiales del INDEC correspondiente a la "Encuesta de Supermercados", mostrando especialmente las diferencias territoriales resultado del uso diferencial y jerárquico del territorio argentino.

Palabras claves: territorio - comercio- supermercados- Argentina

Key words: territory - trade - supermarkets- Argentinean.

\section{Sumario:}

Introducción

\section{Consideraciones metodológicas}

Transformaciones en el comercio supermercadista argentino entre los años 2001-2006.

Análisis territorial del sector supermercadista en Argentina 2001-2006.

Consideraciones Finales

Bibliografía

\section{Introducción}

Estudiar el comercio alimenticio desde el sector supermercadista, lleva a pensar que asistimos al proceso de globalización y modernización, que son especialmente visibles en el comercio de la mano de los grupos de distribución. Claramente este proceso, presenta una tendencia a la homogeneización de pautas, de costumbres, del consumo, etc., pero al mismo tiempo crea una gran cantidad de fracturas y heterogeiniza el espacio. De esta manera se considera que la globalización y la fragmentación son procesos conjuntos, aparentemente contradictorios y opuestos, que se dan de manera intensa y simultánea, en el período actual. "El proceso de globalización con sus flujos acentuadamente unidireccionales se desenvuelve sobre los patrones de crecimiento desigual que caracterizan la expansión capitalista: aunque pretende uniformizar culturalmente, esta lejos de homogeneizar el panorama económico-social tanto a nivel mundial como en el interior de cada nación. Al contrario, provoca incontables procesos de fractura o rompimiento en el espacio-tiempo semejantes a los generados por la cadena taylorista en el trabajo industrial. En este caso, la fragmentación espacio- temporal alcanza el espacio mundial." (Uribe Ortega, G. 1997: 172).

En este sentido se afirma que "el conocimiento del territorio se torna indispensable dado la importancia de los procesos de globalización/fragmentación que se verifican en el mundo contemporáneo. El territorio, modernamente, no es entendido solo como límite político administrativo, sino también como espacio efectivamente usado por la sociedad y por las empresas (...). Todo pasa, pero los territorios, espacios efectivamente usados, permanecen" (Souza, M. A. de 2003: 18).

Entonces esta idea de "uso del territorio", nos lleva a reconocer las diferentes capacidades y posibilidades con que los actores sociales, en este caso las empresas de la gran distribución, actúan 
según las posibilidades y obstáculos ofrecidos por el espacio geográfico, el cual por ser social tiene cargado la historia presente y pasada, y se encuentra en constante proceso de cambio y modificación. En este sentido las empresas usan de manera diferencial el territorio, a partir del dinamismo de la economía y de la sociedad y se crea un orden espacial a partir del uso del territorio que va a responder a un orden económico y a un orden social establecido.

El uso diferencial y jerárquico del territorio, va generando lo que M. Santos denomina los espacios luminosos y los espacios opacos. Las empresas más poderosas, ejerciendo su poder, eligen los puntos que consideran más competitivos, mientras que el resto del territorio es el espacio dejado a las empresas menos poderosas. En realidad existe toda una gama de lugares luminosos y de lugares opacos, disputados por empresas con diferentes grados de modernidad capitalista u organizacional.

Ahora bien, M. Santos (1996) señala que el desarrollo de la globalización en el período actual, necesita de dos brazos, la democracia de mercado y el neoliberalismo; en Argentina, estas condiciones poseen antecedentes desde mediados de los setenta con los gobiernos dictatoriales, se profundizan en los años noventa (con las reformas estructurales y el Plan de Convertibilidad) y se mantienen hasta la actualidad, posteriormente a la devaluación, la cual pareció haber modificado de raíz la economía argentina, pero en realidad su estructura no se modificó . Así J. Sevares (2002), afirma que "en 2001, el orden económico y social neoliberal iniciado en 1975 entró en una crisis profunda pero no terminal. La convertibilidad se derrumbó por sus propias contradicciones y fue sustituida por otro régimen cambiario. Pero el nuevo sistema, no modificó ningún aspecto esencial del orden imperante desde hace más de veinticinco años, como lo demuestra la distribución de beneficios entre los grupos económicos locales y extranjeros, las alianzas tejidas para administrar el cambio y finalmente, pero no menos importante, el alineamiento externo del gobierno interino" (Sevares, J. 2002: 6).

Desde fines del año 2001, con la salida de la Convertibilidad y la violentísima devaluación de la moneda nacional que llevó a que se desplomara el peso fuerte (sobrevaluado), Argentina atravesó una crisis de extraordinaria intensidad, con gravísimas perturbaciones financieras y cesación de pagos sobre parte de la deuda pública. Disuelto el espejismo, "la Argentina volvía a una situación de pobreza que -más allá de las ilusiones alimentadas por la mayor parte de los economistas durante la última década- se encontraba en línea con lo que cualquier observador podía apreciar a simple vista. El poder adquisitivo de la producción argentina en el mercado mundial no era el que indicaba el peso convertible" (Costa, et al. 2004: 2). A pesar de la multiplicación de la pobreza, el proceso devaluatorio fue vehículo para una extraordinaria transferencia de recursos en favor de algunos de los capitales más grandes que operan en la Argentina.

La devaluación inevitable, produjo enormes consecuencias, pero principalmente, redujo los salarios tanto en dólares como en términos de su poder de compra interno; trasladó al Estado una masa de recursos en forma de aranceles a las exportaciones primarias y a la diferencia entre ingresos crecientes y gastos fijos; y sentó las condiciones para una limitada sustitución de importaciones destinada al mercado doméstico. Esta crisis y sus consecuencias se hicieron sentir en el comercio alimenticio y, si bien es claro, que el supermercadismo y la concentración económica de los grupos de distribución en Argentina no se ha revertido, se evidencia desde el año 2001 y con mayor énfasis después de la devaluación (2002) un estancamiento y posterior decrecimiento de este formato a favor de los autoservicios (incluidas las tiendas de descuento) y de los comercios tradicionales de la alimentación (que incluye en estos años, los denominados "todo suelto"). Inclusive se presentan caídas en las ventas de los supermercados que no habían tenido precedentes desde la implantación de éstos en Argentina.

Se presenta en este trabajo, un análisis profundo del sector supermercadista Argentino en el periodo 2001-2006, el cual atravesó un ciclo de crisis profunda presentando importantes diferencias territoriales dentro del país (Se puede encontrar un análisis mas general y también de otros formatos del comercio como autoservicio, almacenes, comercios especializados. en los siguientes trabajos: Di Nucci, J. y Lan, D. 2007a y 2007b).

\section{Consideraciones metodológicas}

Respecto a los datos para estudiar el comercio en Argentina, existe una sola fuente de información sistemática oficial que ofrece información sobre el denominado sector "supermercadista". El INDEC (Instituto Nacional de Estadísticas y Censos), realiza la denominada "Encuesta de supermercados" de periodicidad mensual desde enero de 1997, que es representativa de la actividad de una nómina de empresas de supermercados que cuentan por lo menos con alguna boca de expendio cuya superficie de ventas supere los $300 \mathrm{~m}^{2}$. 
EI INDEC, publica mensualmente los Informes de prensa de la Encuesta de supermercados, por lo cual para utilizar los datos ofrecidos por este organismo, se han debido organizar y sistematizar dichos informes anualmente, desde 1997 a 2006.

De la información ofrecida por el INDEC, se han seleccionado para analizar algunas variables, éstas son: número de bocas de expendio; cantidad de cadenas; superficie de área de venta; ventas por $\mathrm{m}^{2}$, y ventas totales en miles de pesos. Para las primeras cuatro variables, se han agrupado los valores mensuales para cada año y calculado los promedios correspondientes, obteniendo de esa manera un valor representativo de estas variables que rescate las fluctuaciones mensuales durante un año. Para la variable "ventas totales en miles de \$" se ha realizado una sumatoria de los valores mensuales para cada año respectivamente.

Ahora bien, el INDEC elaboró una edición "única" desde que se comenzaron a publicar los informes (enero de 2000) hasta la actualidad, denominada "Relevamiento anual de supermercados" (Información de prensa publicada el 26/2/2004) donde se presentan con mayor desagregación los datos, se diferencia a las cadenas según su tamaño, en dos tipos, cadenas grandes y cadenas medianas y a éstas por tamaño de las bocas. Estos datos ofrecidos por el INDEC corresponden a dos momentos: "mayo de 1999" y "mayo de 2003", que coinciden con dos situaciones bien diferentes en el país y en el sector "supermercadista" en particular, por lo que resulta interesante analizarlos ya que es la única información de la brindada por el INDEC que permite realizar algunas diferenciaciones hacia el interior del formato supermercado.

Para el INDEC entonces, las cadenas pueden ser "grandes" o "medianas", considerando que las primeras facturan (al momento de su inclusión en la encuesta) más de \$20 millones por mes, y las segundas son las que facturan hasta dicho valor.

EI INDEC, diferencia a las bocas de expendio según su superficie de venta de la siguiente manera: bocas de hasta $500 \mathrm{~m}^{2}$; bocas entre 501 y $1000 \mathrm{~m}^{2}$; bocas entre 1001 a $4000 \mathrm{~m}^{2}$ y bocas de más de $4000 \mathrm{~m}^{2}$. De esta manera, un supermercado es todo formato que posea más de $300 \mathrm{~m}^{2}$ en su superficie de venta, lo cual incluye a los hipermercados (que se corresponderían con las bocas de más de $4000 \mathrm{~m}^{2}$ ), a los supermercados (pudiendo incluir a las bocas entre 501 a $4000 \mathrm{~m}^{2}$ ) y también a los formatos denominados como autoservicios (bocas de hasta $500 \mathrm{~m}^{2}$ ), aunque existen autoservicios tipo Tiendas de Descuento (Hard Discount) o independientes, que pueden tener menos de $300 \mathrm{~m}^{2}$, y que entonces no son tomados en el relevamiento efectuado por el INDEC.

El nivel de cobertura del relevamiento en términos de superficie de los salones de ventas, es el siguiente:

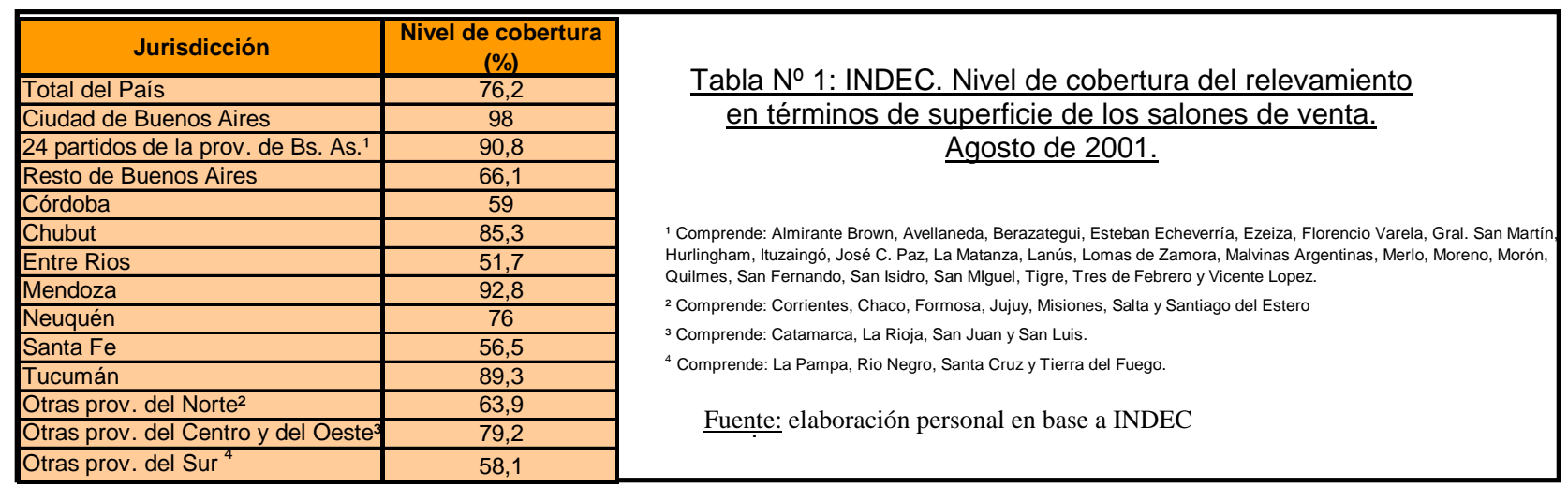

Desde el año 2001, el INDEC presenta algunas variables diferenciando según estas "unidades espaciales", lo que permite analizarlas territorialmente; claramente el grado de agregación o desagregación espacial tomado, responde al grado de concentración espacial de las principales cadenas de supermercados. Respecto a las unidades espaciales, se debe mencionar que desde el año 2003, el INDEC, separa de la denominada "otras provincias del norte", a la provincia de Salta y comienzan a presentarse los datos de manera diferencial.

Ahora bien, este relevamiento, realizado por el INDEC no toma en cuenta a los formatos menores, por lo cual es necesario mencionar que al ser éstos los únicos datos oficiales, en Argentina en general, se estudia y se evalúa la situación del comercio minorista de la alimentación a través del análisis único de los supermercados (aunque esta estadística hace referencia en algunas oportunidades a lo sucedido en los demás formatos, especialmente en los comercios tradicionales). 
Para la geografización de la información se usan Sistemas de Información Geográfica que permite la digitalización, ingreso, procesamiento y análisis de datos para la posterior presentación de los resultados mediante el diseño y elaboración de cartografía temática correspondiente. Se han elaborado "mapas de símbolos graduados", que demuestran a partir del tamaño de una variable visual seleccionada las diferencias entre valores o cantidades (absolutos o porcentuales), como por ejemplo "número de bocas de expendio según unidades de análisis". También se han elaborado "mapas con gráficos", a partir de los cuales es posible analizar el comportamiento de múltiples variables y de series temporales, empleando para ello gráficos de barras y de sectores circulares, que hacen referencia a las unidades espaciales seleccionadas para este análisis. Por ejemplo se ha analizado la "variación por $\mathrm{m}^{2}$ entre los años 2001-2006", y "participación (\%) en el total de las ventas de los supermercados según unidades espaciales".

\section{Transformaciones en el comercio supermercadista entre los años 2001-2006.}

A partir de la recesión económica y especialmente desde la mencionada crisis iniciada en el año 2001, se comienzan a evidenciar algunos cambios en el comercio de la alimentación Argentina (que se hicieron fuertes en los momentos de profundización de la crisis, pero que se mantuvieron como tendencias generales hasta la actualidad.

Gráfico № 1: Ventas de Supermercados a precios constantes $^{1}$. Serie desestacionalizada y Tendencia del Ciclo. Argentina. 1996-2006.

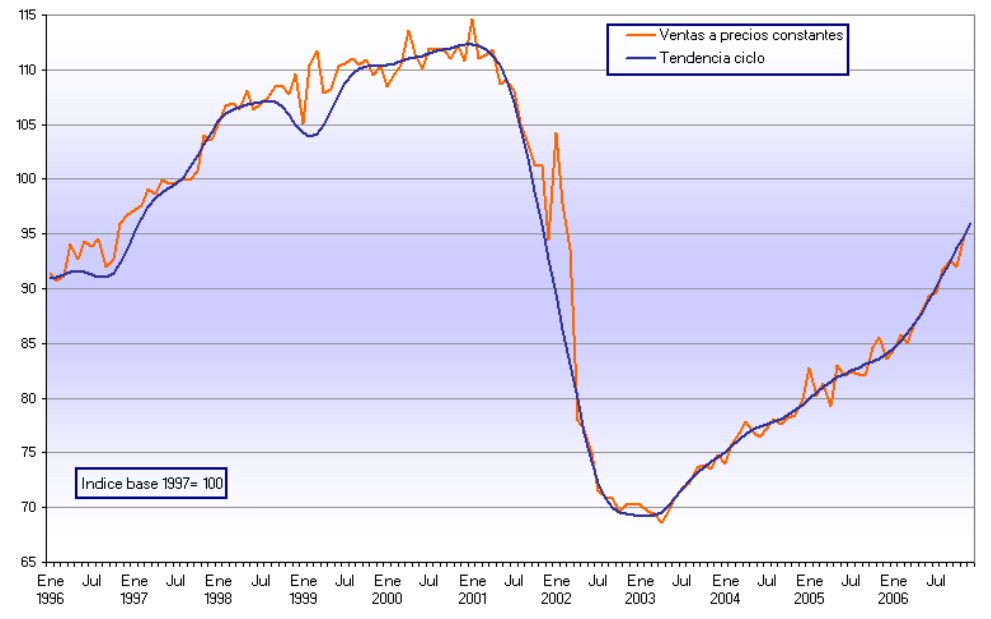

Fuente: elaboración personal sobre la base de INDEC. Encuesta de Supermercados. 1/06 y 5/07. los sistemas informáticos financieros, los paros y movilizaciones, la grave situación antes, durante y después de los saqueos y las dos crisis institucionales con las renuncias de dos jefes de Estado en forma consecutiva, ha provocado una parálisis total en la comercialización de productos y servicios".

A pesar que algunos meses presentan un crecimiento en los valores índices de ventas, se observa que la "tendencia del ciclo" es a la baja; así, por ejemplo el índice de ventas presenta un valor de 111,8 en abril del 2001, de 78 en abril de 2002 y de 68,9 en abril de 2003; siendo éste último valor el más bajo de todo el periodo en estudio.

Es interesante señalar que el mes de junio de 2002 presentó una caída del 28\% de las ventas (respecto al mismo mes del año anterior), pero dicha disminución fue mayor en hipermercados y supermercados, que en los autoservicios y comercios tradicionales de barrio, debido a que "los primeros suelen actualizar precios con mayor celeridad que los segundos" (CAME 30/6/2002).

También la Cámara Argentina de Comercio, señala para ese año las mismas tendencias que se han mencionado: "el comercio minorista se encuentra frente a una posición comprometida. Por un lado, los costos se han incrementado como consecuencia del aumento en los precios que fijan los proveedores y la reducción en los plazos de financiamiento. Por el otro, la falta de liquidez, el desempleo, la ausencia de una moneda confiable y la incertidumbre reinante han profundizado la contracción de la demanda. Esta coyuntura origina que 6 de cada 10 comerciantes consultados considere que la situación empeorará en el corto plazo" (CAC. 5/2002). 
Muchas de las tendencias (re)surgidas durante el año 2002 se mantienen y profundizan durante el año 2003, aunque como se ha presentado en el gráfico № 1 , se da una tenencia alcista en las ventas: "recién en el primer trimestre del año 2003 la economía argentina vuelve exhibir una tasa de crecimiento positiva que según el MECON fue de $+5 \%$, valor superado durante el segundo trimestre $(+8 \%)$, trayendo un mejoramiento en los niveles de desempleo (la tasa de desocupación en mayo de 2003 se situó en 15,6\%) en un marco de estabilidad de precios" (MECON. Subsecretaria de Defensa del Consumidor. 10/2003: 79).

Respecto a este año 2003 y observando el gráfico $N^{\circ} 1$, resulta interesante mencionar que en el primer cuatrimestre los supermercados continúan registrando bajas en sus ventas, (aunque la caída se había desacelerado), siendo la actividad de los supermercados, unas de las "mas lentas en reaccionar". A partir de este año, las ventas en supermercados dejaron de caer y comienzan a crecer pero de manera muy lenta, lo que lleva, a partir de mediados de ese año, a que la tendencia del ciclo sea alcista aunque sin llegar a los valores índices de los noventa, inclusive presentando siempre valores menores al índice base 100, de agosto de 1997.

El repunte de las ventas en hipermercados se debe a, "las agresivas promociones lanzadas especialmente por las grandes cadenas, que ofrecen descuentos al 15\%, según la forma de pago o el rubro de las mercaderías" (MECON. Monitoreo Sectorial. 6/2003: 16). Además, estos canales de la GD ampliaron la oferta de "marcas propias", incursionaron en carnes, toda clase de alimentos y artículos de limpieza. Sin embargo, el MECON agrega que "se observa que los consumidores retomaron la compra de alimentos y bebidas en almacenes de barrio, que otra vez vuelven a representar más de la mitad de la provisión de la canasta básica del país. Los super e hipermercados, que llegaron a tener más de $80 \%$ del mercado, se redujeron hasta el 38\%" (MECON. Monitoreo Sectorial. 12/2003: 19).

Volviendo al gráfico $N^{0} 1$, se puede observar que a partir del año 2004, comienza una lenta pero progresiva recuperación del índice de ventas de los supermercados, permitiendo una tendencia de ciclo en alza, la cual presenta un crecimiento más abrupto recién durante el año 2006. Para el año 2004 el INDEC, señala que las cifras del sector supermercadista no son buenas y a pesar que el consumo en general crece lentamente y va en aumento, los supermercados tardan en recuperarse sin lograr llegar a los niveles pre-crisis; se señala así que en el primer bimestre de 2004, las ventas crecieron a precios constantes pero no logran recuperar la participación que tenían en el comercio minorista.

Para el mes de octubre de 2004, el INDEC señala que las ventas de supermercados lograron aumentar en un $2.5 \%$ frente a septiembre (desestacionalizada y a precios constantes); "De acuerdo con la información suministrada por el INDEC, en la comparación contra octubre de 2003 las ventas de los supermercados crecieron el 6,1 por ciento. En los últimos doce meses, los precios de las grandes cadenas aumentaron el 6,2 por ciento, es decir, estuvieron por encima de la inflación, que en el mismo período fue del 5,7 por ciento. Ambos factores determinaron que la facturación creciera el 13,5 por ciento. (...). Lo concreto es que las ventas de los supermercados, medidas en unidades vendidas, aún están casi un 30 por ciento por debajo de las de mediados de 2002, cuando el sector era afectado de lleno por la crisis de salida de la convertibilidad. Durante 2004, los supermercados nunca pudieron consolidar una tendencia alcista. La evolución mensual fue siempre volátil" (Página 12. Diario. $26 / 11 / 2004)$.

En los primeros meses del año 2005, comienza a percibirse un incremento en el consumo de productos alimenticios consecuencia especialmente de los aumentos salariales impulsados por el gobierno nacional particularmente en los sectores de menor poder adquisitivo (para los cuales el consumo de productos de almacén tiene un peso relativamente alto, en su consumo total). A fines de este año, se observa un fuerte aumento de ventas, debido especialmente a las subas salariales, la cercanía a las fiestas y las posibilidades de compras, "en los últimos cuatro meses, las ventas crecieron a un promedio interanual cercano a 7\%, muy por encima del promedio anual y deja buenas expectativas en el comienzo de 2006" (CAME. 4/12/2005).

Con respecto al año 2006, se observa en el gráfico № 1 , que las ventas continúan en aumento, pero este año, y especialmente la segunda parte del mismo, se diferencia de los años anteriores en cuanto al abrupto crecimiento de las mismas, presentando valores índices similares a los del año 1997, aunque dicha recuperación no alcanza a los altos valores correspondientes a los años pre-crisis.

De esta manera, en este breve análisis, se presentó la situación general de los supermercados en Argentina, con datos generales para todo el país, pero claramente se dan importantes diferencias 
territoriales en nuestro país resultado de las disparidades ya existentes y del uso diferencial y jerárquico del territorio por parte de de los supermercados.

\section{Análisis territorial del sector supermercadista en Argentina 2001-2006.}

Las desigualdades territoriales existentes en Argentina, también se ponen en evidencia en el comercio alimenticio de la alimentación y en especial en el sector de la GD. La distribución de los locales de supermercados en Argentina en busca del consumo masivo, acompaña a la distribución de la población, coincidiendo con las ciudades de mayor importancia, no solo en cantidad de población

Grafico No 2: Supermercados Argentina. Cadenas y bocas de expendio. 2001-2006.

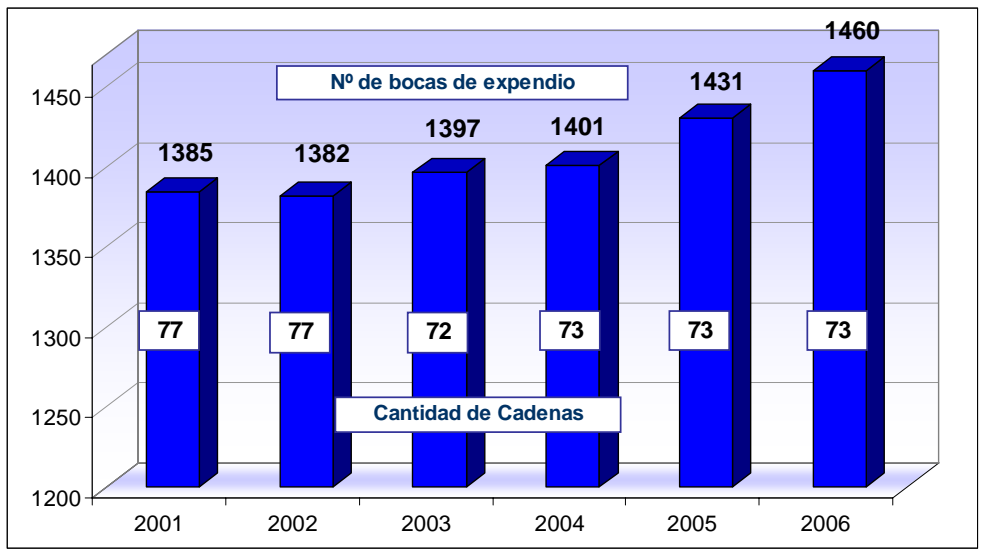
sino también en poder adquisitivo, lo que significa un importante número de potenciales consumidores. Esto implica, una importante concentración de la GD en la ciudad de Bs. As (Cap. Federal), en los 24 partidos del Gran Buenos Aires (GBA), en el resto de la provincia de Buenos Aires y, en Córdoba.

El gráfico $\mathrm{N}^{\circ} 2$, establece la cantidad de cadenas relevadas y el número de bocas de expendio correspondientes, entre los años 2001 y 2006, para el total del país.

Se observa que han ido variando la cantidad de cadenas de

Fuente: elaboración personal sobre la base de INDEC "Encuesta de supermercados".

supermercados y los locales correspondientes; resulta necesario remarcar que para el año 2000, el INDEC registró 1234 bocas pertenecientes a 77 cadenas de supermercados, lo cual demuestra un importante crecimiento de bocas, 151 entre el 2000 y el 2001, para la misma cantidad de cadenas, relación que se mantiene para el año 2002. A partir del año 2003, la cantidad de cadenas relevadas por el INDEC disminuye y las bocas de expendio aumentan aunque más lentamente que lo ocurrido en los últimos años de la década de los noventa (en el año 1997, 85 cadenas de supermercados poseían 804 bocas de expendio, en el año 2000, 77 cadenas poseían 1234 bocas de supermercados). Obsérvese que desde el año 2004, cuando la situación económica del país presenta mejoras y los supermercados comienzan a "reaccionar", la misma cantidad de cadenas (73), presentan un crecimiento anual de alrededor de 30 bocas de supermercados.

Ahora bien, respecto al análisis intraformato, la Encuesta de Supermercados relevó, para el mes de mayo de 2003, 70 empresas (cadenas de supermercados), entre las que se distinguen 11 cadenas grandes y 59 cadenas medianas, según el monto de las ventas.

Respecto a la cantidad de bocas para el total de las cadenas (sin diferenciar aún entre

Mapa № 1: Supermercados Argentina. Número de bocas de expendio seqún unidades espaciales INDEC. 2006

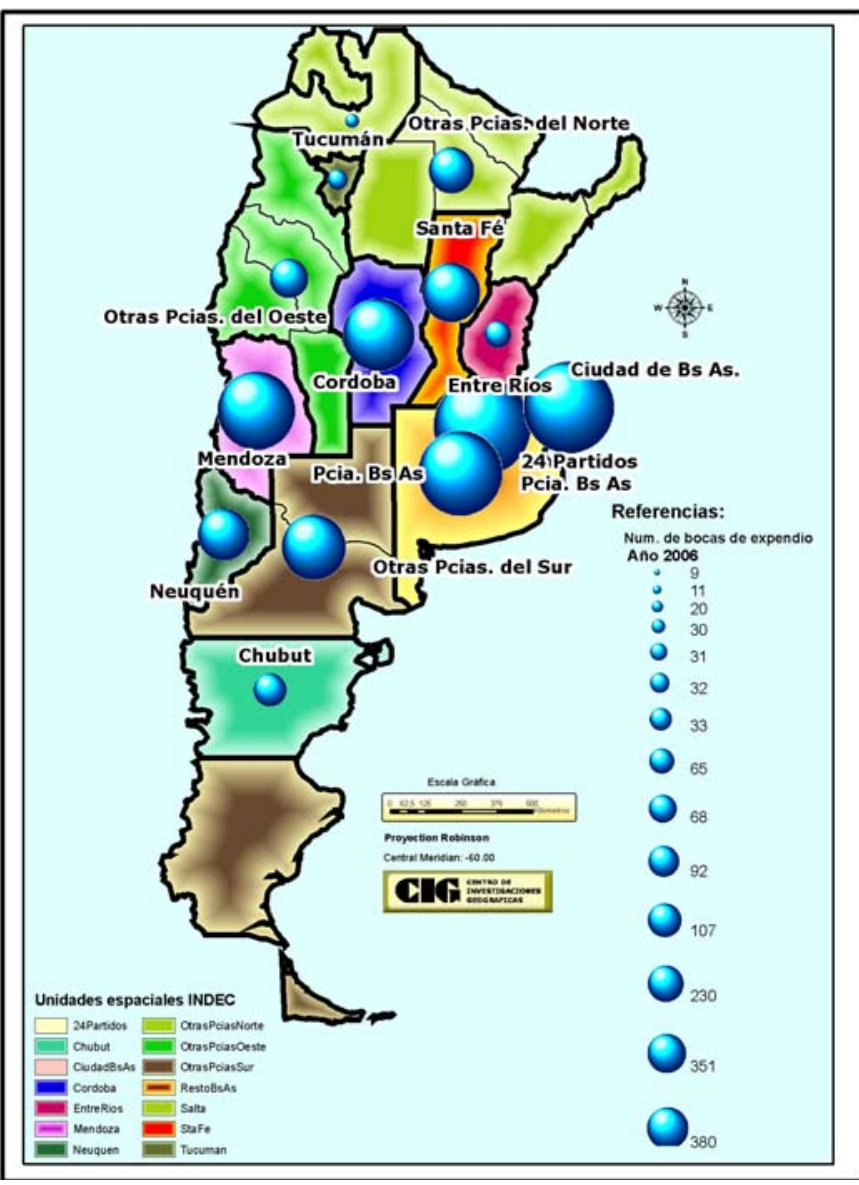

Fuente: elaboración personal sobre la base de INDEC "Encuesta de supermercados" 1/06 a 01/7. 
grandes y medianas) en mayo de 1999 el número era de 1039 y cubrían una superficie en $\mathrm{m}^{2}$ de 1.884.079, mientras que para el mismo mes del 2003 , la cantidad de bocas era de 1.424 , cubriendo un total de $2.053 .530 \mathrm{~m}^{2}$; lo cual implica un crecimiento de $37,1 \%$ en el número de bocas y un incremento de $21,9 \%$ en la superficie, de manera que el tamaño promedio de las bocas disminuyó $11 \%$.

A las 11 cadenas grandes relevadas en mayo de 2003 le corresponden 677 bocas de expendio en todo el país, y a las 59 cadenas medianas 747 bocas, lo que significa que solo 11 cadenas poseen el $47.5 \%$ de todas las bocas de supermercados.

En el año 2006, las bocas de expendio registradas en el territorio argentino son 1460 (pertenecientes a 73 cadenas de supermercados); el mapa $\mathrm{N}^{\circ} 1$, referencia territorialmente estas bocas.

La concentración de las bocas de expendio de estas 73 empresas, se dan en los 24 partidos del GBA, seguidos por la ciudad de Buenos Aires y el resto de la prov. de Bs. As., que concentran el $65.8 \%$ de estos locales de supermercados. Las provincias de Mendoza (107 bocas), Córdoba (92 bocas) y Santa Fe (65 bocas) reúnen el $18.9 \%$ de las bocas de todo el país, por lo cual en estas unidades espaciales mencionadas, se encuentran el $83.9 \%$ del total de los locales de supermercados del país.

Grafico № 3: Supermercados Argentina. "Superficie del área de ventas" (en m² $\underline{2}$. 2001-2006.

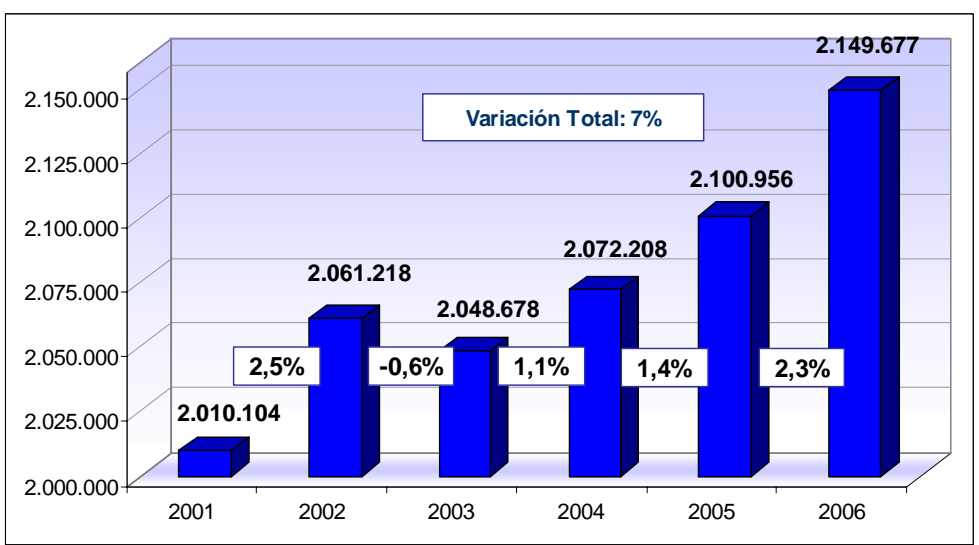

Fuente: elaboración personal sobre la base de INDEC "Encuesta de supermercados".

cual es muy bajo a la comparada, por ejemplo, con el correspondiente al período de años 1997-2000, que fue del $45.8 \%$. La variación interanual de la "superficie del área de ventas" venia decreciendo, siendo de $8.8 \%$ entre 1999 y 2000; sin embargo, este porcentaje es muy bajo a partir del 2001, hasta llegar a ser negativo entre 2002 y 2003 (a pesar de registrarse 15 bocas de expendio más), como resultado de la crisis económica, que como se ha señalado, afecto de manera profunda a los supermercados. Este bajo crecimiento porcentual del área de ventas significa además, que las

Gráfico No 4: Supermercados Argentina. "Superficie del área de ventas" según tamaño de las bocas (\%). Mayo 1999 - Mayo

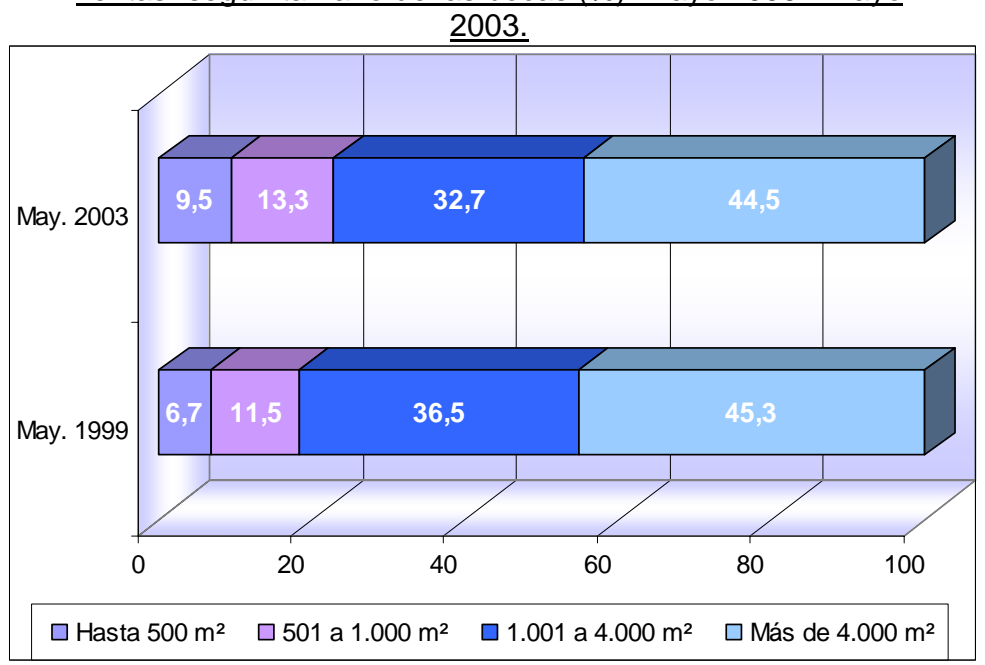

locales de supermercados poseen cada vez menores superficies.

Para realizar un análisis más profundo de esta variable, se presenta el gráfico $\mathrm{N}^{\circ} 4$, con la variación en la "superficie del área de venta" (en $\mathrm{m}^{2}$ ), en los dos momentos mayo de 1999 y mayo de 2003, diferenciando por tamaño de supermercados:

Con respecto a la "superficie del área de ventas", son los hipermercados (más de $4.000 \mathrm{~m}^{2}$ ), los que contribuyen en los dos momentos con la mayor superficie de los salones de venta. Sin embargo, "la superficie de los

Fuente: elaboración personal sobre la base de INDEC. Encuesta de Supermercados. 26/2/2004 
estratos de más $1.000 \mathrm{~m}^{2}$ verificó un decrecimiento conjunto en su participación, desde $81,8 \%$ en el año 1999, a 77,2\% en 2003" (INDEC. 26/2/2004: 5). La caída en la participación de la "superficie del área de ventas" de los supermercados más grandes (entre 1001 a $4000 \mathrm{~m}^{2}$ ), fue a favor de los supermercados de menores dimensiones (menos de $1000 \mathrm{~m}^{2}$ ).

Ahora bien, diferenciando según tamaño de las cadenas, el INDEC señala que en las grandes cadenas entre los dos momentos analizados, no se presentan importantes cambios respecto a la participación de cada estrato en la "superficie del área de ventas". Además "el estrato de más de $4.000 \mathrm{~m}^{2}$ continuó ubicándose en el primer lugar con $54,8 \%$ de la superficie total en mayo de 2003" (INDEC. 26/2/2004). Respecto a las cadenas medianas, los dos estratos de menor tamaño aumentaron su participación en la superficie del área de ventas. "Se destaca el estrato de bocas de hasta $500 \mathrm{~m}^{2}$, que pasó de tener una participación de $21 \%$ en mayo de 1999 , a 33,2\% en mayo de 2003, reemplazando al estrato de bocas de 1.001 a $4.000 \mathrm{~m}^{2}$ como el de mayor participación. En la anterior medición, las bocas de hasta $1.000 \mathrm{~m}^{2}$ aportaban el $43,4 \%$ de la superficie. En mayo de 2003 aportaban el 62\%" (INDEC. 26/2/2004).

Este análisis más desagregado por tipo de cadena y tamaño de los supermercados, permite justificar mejor que la variación anual en el crecimiento de la superficie del área de ventas (para el total de las cadenas en Argentina), haya sido muy baja entre los años 2001-2006 como se ha presentado en el grafico № 3; además, se corrobora lo señalado respecto a la disminución en el tamaño promedio de las bocas.

El mapa $N^{0} 2$, representa las diferencias territoriales en la variación de la "superficie del área de

Mapa № 2: Supermercados Argentina. Variación en la "superficie del área de ventas" según unidades espaciales. $2001-2006$.

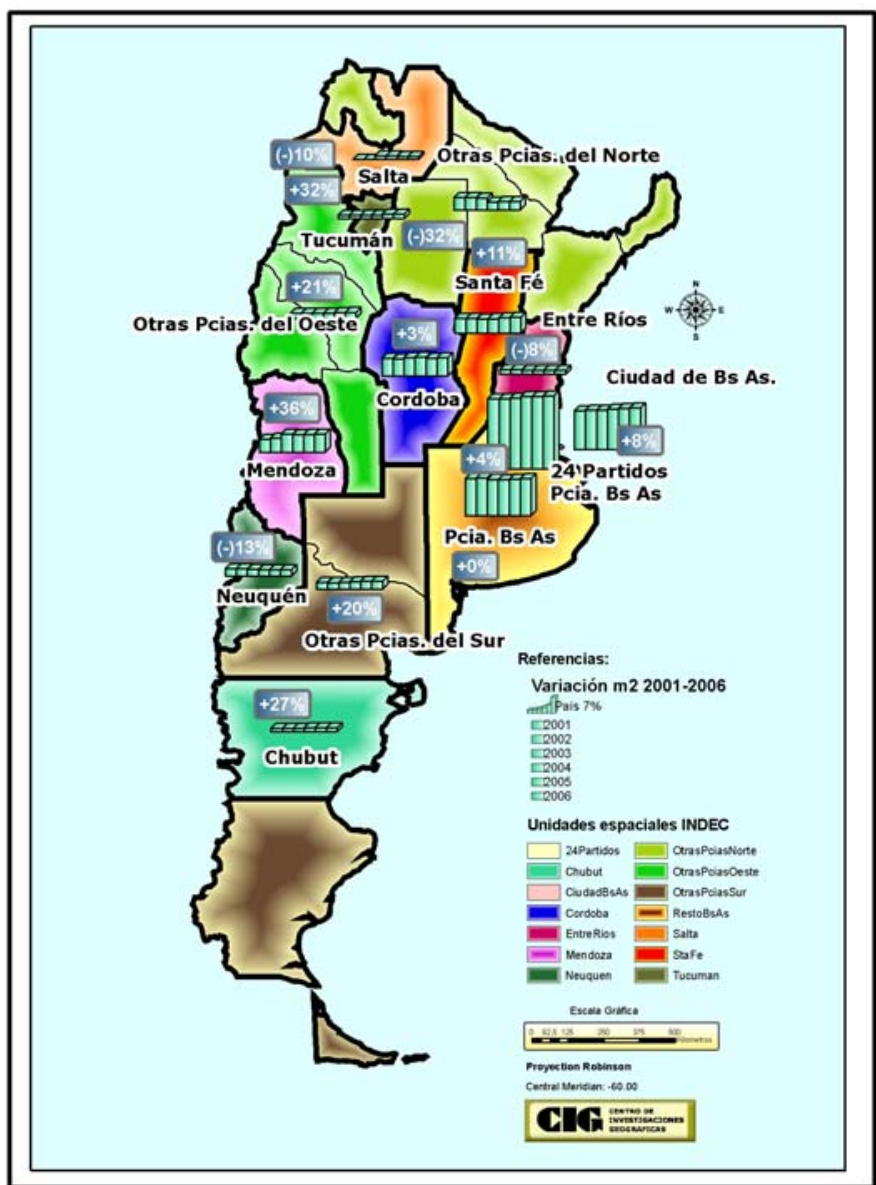

Fuente: elaboración personal sobre la base de INDEC "Encuesta de supermercados". 12/2000 a 1/2007. venta" entre los años 2001 y 2006.

Se observa en el mapa № 2 , que el mayor aporte de superficie de supermercados en Argentina, lo dan en primer lugar los 24 partidos del GBA, en segundo lugar, la ciudad de Bs. As y en tercer lugar, el resto de la prov. de Bs. As.

Sin embargo puede observarse que para esta variable, las diferencias entre el GBA y las demás jurisdicciones son muy significativas; así para el año 2006, el promedio de la superficie del área de ventas del GBA es de $627.591 \mathrm{~m}^{2}$ (con 380 bocas de expendio), mientras que la ciudad de Buenos Aires presenta un valor de aproximadamente la mitad que el GBA, $354.694 \mathrm{~m}^{2}$ (con 351 bocas de expendio). Esta diferencia se explica porque en el GBA hay supermercados de grandes superficies, siendo especialmente hipermercados los que se instalan en estos partidos con grandes densidades poblacionales, ubicados en las afueras de estas ciudades y a lo largo de los ejes de entrada y salida de las ciudades.

Como se ha mencionado, la variación porcentual entre 2001 y 2006, para todo el país, fue del $7 \%$ pudiendo observarse en el mapa № 2, que el GBA, y Córdoba, presentan variaciones porcentuales con valores inferiores al promedio aunque siguen creciendo; la ciudad de Buenos Aires, presenta un valor muy cercano al promedio y en la prov. de Bs. As., no se registran variaciones en la superficie del 
área de ventas. El sector supermercadista ya se encuentra muy desarrollado en estas unidades espaciales y además se registran aperturas de nuevas bocas de superficies menores.

Pero en estos años, las cadenas de supermercados comienzan a abrir bocas en otras ciudades, dándose la expansión territorial hacia el interior del país, por lo cual puede observarse en el mapa que hay unidades espaciales que crecen por encima del promedio del país, como son los casos de Mendoza (+36\%), Tucumán (+32\%), Chubut (+27\%), Santa Fe $(+11 \%)$ y también las "otras prov. del sur" $(+20 \%)$ y otras prov. del oeste $(+21 \%)$. Por ejemplo, para el caso de la provincia de Mendoza que presenta el mayor porcentaje de crecimiento, los datos del INDEC señalan 78 bocas de expendio en el año 2001, pasando a 107 bocas en el 2006; la llegada de grandes supermercados, modifica profundamente esta variable, ya que en el año 2000 se instalan tres hipermercados, Wal-Mart, Carrefour y Libertad, y en el año 2001 se instalan otros dos hipermercados, que son una segunda sucursal de Libertad, y un Jumbo (datos extraídos de las sitios web oficiales de las empresas).

Por otro lado, se observa que en algunas unidades espaciales la variación en la "superficie del área de ventas" presenta un valor negativo, como son Neuquén (-13\%), Entre Ríos (-89\%), Salta (-10\%) y "otras prov. del norte" (-32\%). En estas unidades espaciales en el mismo período también disminuyeron el número de bocas de expendio, lo cual explica la caída de la superficie del área de venta. Tomando como ejemplo el caso de Neuquén, los datos del INDEC, muestran que en el año 2001 había 39 bocas con $60.963 \mathrm{~m}^{2}$ y en el 2006, 33 bocas con $53.026 \mathrm{~m}^{2}$; estas caídas pueden explicarse porque en la ciudad de Neuquén se instalaron 4 grandes hipermercados entre fines de la década de los noventa y el año 2002, lo cual sumado a la crisis económica, produjo el cierre de locales de algunos supermercados de cadenas regionales, como es el caso de Supermercados Topsy.

Para el caso de las "otras prov. del norte", se observa también una reducción en el número de bocas de expendio en este período de años, pasando de 45 a 32 locales; en la provincia de Salta, esta reducción también ocurre, existiendo 12 bocas en el año 2003 y 9 en el 2006, siendo la variación altamente negativa por tratarse de cantidades bajas, sobre las cuales el cierre de dos supermercados de grandes dimensiones impacta altamente en esta variación porcentual.

Para poder seguir profundizando en este análisis, en el gráfico $N^{0} 5$, se toma una variable central "ventas totales en miles de pesos", es decir la facturación de los supermercados en este período de años, para el total del país:

Grafico No 5: Supermercados Argentina. "Ventas totales anuales" (en miles de $\$$ a precios corrientes). 2001-2006

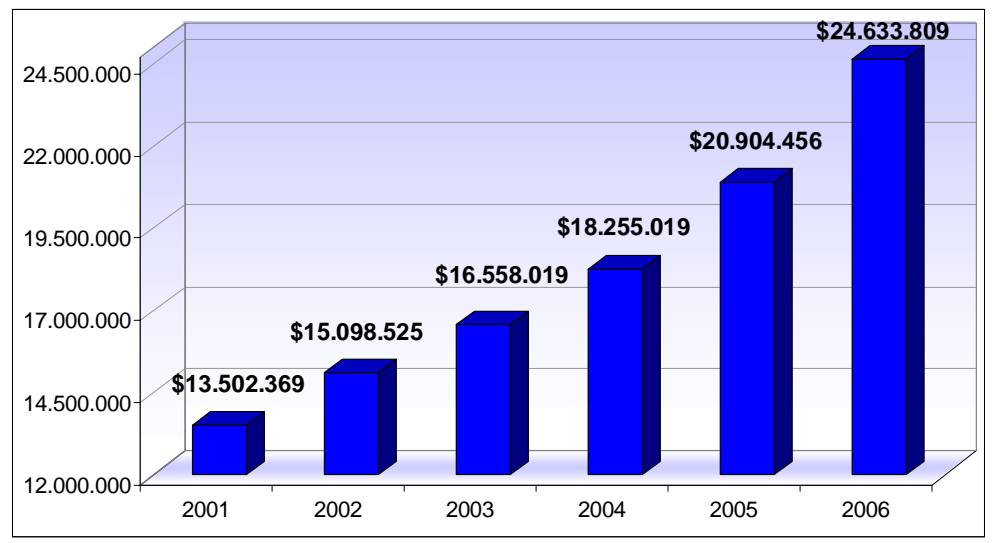

Fuente: elaboración personal sobre la base de INDEC "Encuesta de supermercados". 2/2001 a 1/2007

Antes de analizar este gráfico, es necesario señalar que el índice de ventas de los últimos 10 años, desestacionalizado y a precios constantes, muestra una fuerte caída de este índice, durante la crisis 2001-2002, y la lenta recuperación en los años posteriores, llegando a los valores índices de los años pre-crisis recién en el segundo semestre del 2006.

Ahora bien, los datos presentados en el gráfico $\mathrm{N}^{\circ} 5$, corresponden a las sumas anuales (en \$) de las ventas de los supermercados en Argentina medidas a precios corrientes, lo cual significa que se percibe en estos valores, los efectos inflacionarios de la devaluación de la moneda desde el 2002, y la inflación de los precios de los últimos años.

Realizada esta aclaración, y observando el gráfico, se percibe que entre los años 2001 y 2006 , la variación porcentual en la facturación de los supermercados es del 82,4%; además, las ventas medidas en miles de pesos, cayeron en el año 2001 respecto al 2000 por efecto de la crisis económica, pero comienzan a recuperarse especialmente después del 2003, observándose un importante crecimiento entre los años 2005 y 2006. 
Ahora bien, la variación de la facturación entre los años 2001 y 2006, presenta también diferencias territoriales, como pueden apreciarse en el mapa $\mathrm{N}^{\circ} 3$ :

Mapa № 3: Supermercados Argentina. Variación en las "ventas totales anuales" (en miles de \$ a precios

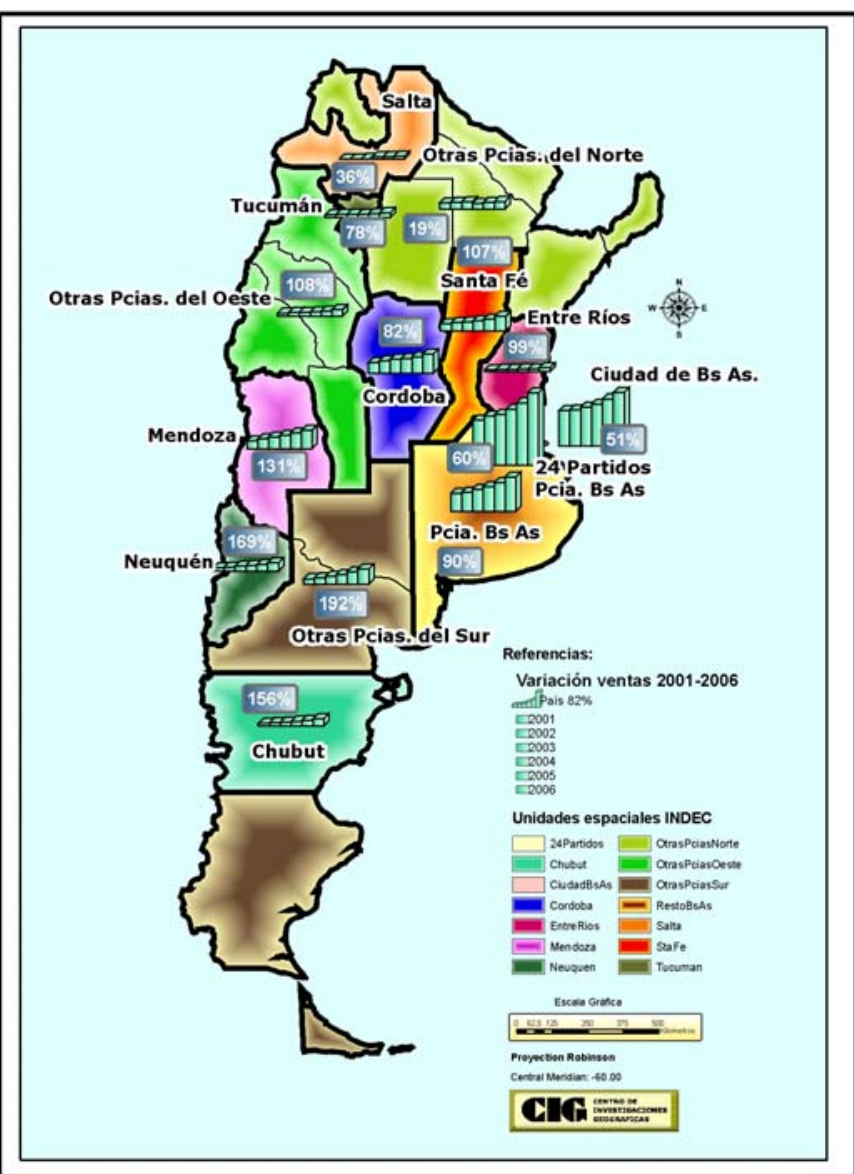

Fuente: elaboración personal sobre la base de INDEC "Encuesta de supermercados". 2/2001 a 1/2007.
Los datos del mapa nos muestran que hay unidades espaciales que presentan un crecimiento en la facturación muy por encima del promedio del país (que fue del $82 \%$ ), existiendo además, otras con valores por debajo de este promedio.

El GBA y la ciudad de Bs. As., presentan una variación porcentual por debajo del promedio del país, demostrando un estancamiento en su crecimiento en cuanto a facturación, aunque los supermercados presentan altos valores de ventas.

La provincia de Córdoba, por ejemplo, presenta una variación en su facturación con un valor igual al promedio del país (ver mapa $N^{\circ} 3$ ), lo cual puede explicarse por saturación del mercado supermercadista si observamos además que en el mapa $\mathrm{N}^{\circ} 2$ en este período de años, el crecimiento en la superficie del área de ventas fue solo de un $3 \%$.

La variación porcentual presenta valores más altos que el promedio nacional, en Neuquén (163\%), Chubut (156\%), Mendoza (131\%), Santa Fe (107\%), "otras prov. del sur" (192\%), "otras prov. del oeste" (108\%), Entre Ríos (99\%) y prov. Buenos Aires (90\%); estos valores porcentuales son muy altos en algunas provincias porque parten de situaciones con valores muy bajos, lo cual determina un fuerte crecimiento, pero además se pone en evidencia, como ya se ha mencionado, el desarrollo del supermercadismo en el interior del país, determinado por el estancamiento de la facturación en lugares con más tradición supermercadista, como la Capital Federal, el GBA y Córdoba, y la búsqueda por parte de las empresas de nuevos potenciales consumidores, en nuevos mercados.

Resulta interesante seguir ejemplificando esta situación con el caso de la provincia de Neuquén, en la cual se había señalado una caída en el número de bocas y una variación negativa en la superficie del área de ventas; sin embargo presenta el valor más alto 163\%, en el crecimiento de la facturación entre 2001 y 2006. Esto significa que existe una concentración de las ventas en una menor cantidad de grandes supermercados, particularmente en 4 hipermercados (de más de $4.000 \mathrm{~m}^{2}$ ), 1 Jumbo, 1 La Anónima, 1 Wal Mart y 1 Norte, que para mayo de 2003 concentraban el 67,5\% de la superficie, y el $50 \%$ de las ventas (en miles de pesos) de los supermercados de la provincia de Neuquén (INDEC. Encuesta de Supermercados. 26/2/2004: 15, e información de los sitios web de las empresas).

Los valores más bajos en la variación de las ventas en este periodo, se dan en "otras prov. del norte" (19\%) y en Salta (36\%) lo cual debe relacionarse con el decrecimiento en la "superficie del área de ventas" y la reducción del número de bocas.

La ultima variable tomada aquí de las brindadas por el INDEC, para el análisis de la situación de los supermercados en el país entre los años 2001-2006, es las "ventas por $\mathrm{m}^{2}$ ", las cuales aumentan "si crecen las ventas y disminuyen los $\mathrm{m}^{2}$, o si las ventas crecen más que los $\mathrm{m}^{2 \prime}$. Los promedios anuales de las "ventas por $\mathrm{m}^{2}$ ", se analizan en el gráfico № 6 . 
Grafico No 6: Supermercados Argentina. Variación en las "ventas por $\mathrm{m}^{2}=$ (\$) 2001-2006.

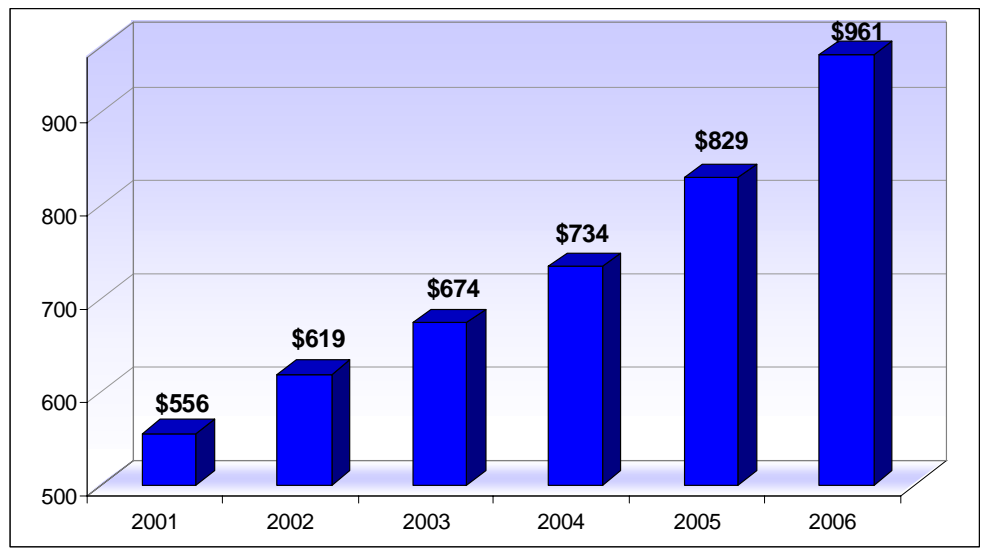

Fuente: elaboración personal sobre la base de INDEC "Encuesta de supermercados". 2/2001 a 1/2007
Se observa el crecimiento anual de las ventas por $\mathrm{m}^{2}$ de los supermercados en Argentina, cuya variación entre 2001 y 2006, es de $73 \%$.

Las "ventas por $\mathrm{m}^{2 \text { " venían }}$ disminuyendo desde el año 1997 presentando los valores más bajos en los años 2001 y 2002 con la profundización de la crisis, para comenzar a crecer a partir del año 2003, debido básicamente al aumento de la facturación en las ventas. Recién en el año 2006, las

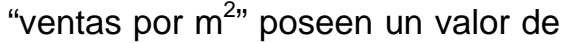
$\$ 961$, superando al valor máximo que había sido el del año 1997, con $\$ 862$ por $\mathrm{m}^{2}$.

Las "ventas por $\mathrm{m}^{2}$ " se diferencian también según el tamaño de las bocas de supermercados, por lo cual se presenta a continuación la tabla $N^{\circ} 1$, con esta variable ( $\mathrm{y}$ otras complementarias) que permiten realizar un análisis más detallado hacia el interior de los supermercados, en los dos momentos seleccionados, mayo de 1999 y mayo de 2003:

Tabla № 2: Supermercados Argentina. Comparación entre mayo de 1999 y mayo de 2003 , por tamaño de las bocas, según variables seleccionadas.

\begin{tabular}{|c|c|c|c|c|c|c|c|c|}
\hline \multirow[t]{2}{*}{ Tamaño de las bocas } & \multicolumn{2}{|c|}{$\begin{array}{c}\text { Número de } \\
\text { operaciones (\%) }\end{array}$} & \multicolumn{2}{|c|}{$\begin{array}{l}\text { Ventas por } \\
\text { operación (\$) }\end{array}$} & \multicolumn{2}{|c|}{$\begin{array}{c}\text { Número de } \\
\text { operaciones por } \mathrm{m}^{2} \\
\text { (numero) }\end{array}$} & \multicolumn{2}{|c|}{ Ventas por $\mathrm{m}^{2}(\$)$} \\
\hline & May-99 & May-03 & May-99 & May-03 & May-99 & May-03 & May-99 & May-03 \\
\hline Todas las cadenas & 100 & 100 & 20,9 & 21,8 & 33,4 & 29,8 & 698 & 652 \\
\hline Hasta $500 \mathrm{~m}^{2}$ & 11,7 & 19,7 & 9,1 & 9,8 & 58,1 & 61,5 & 528 & 605 \\
\hline 501 a $1.000 \mathrm{~m}^{2}$ & 22,1 & 22,1 & 12,5 & 14,9 & 64,4 & 49,5 & 802 & 736 \\
\hline $1.001 \mathrm{a} 4.000 \mathrm{~m}^{2}$ & 42,1 & 38,9 & 18,9 & 21,4 & 38,6 & 35,5 & 730 & 761 \\
\hline Más de $4.000 \mathrm{~m}^{2}$ & 24,1 & 19,3 & 37,7 & 42,9 & 17,8 & 13 & 671 & 556 \\
\hline
\end{tabular}

Fuente: elaboración personal sobre la base de INDEC. Encuesta de Supermercados. 26/2/2004.

El "número de operaciones" (en \%) se incrementaron 8,8\% durante el período estudiado; se observa en la tabla $\mathrm{N}^{\circ} 2$, que las bocas de 1.001 a $4.000 \mathrm{~m}^{2}$ continuaron concentrando la mayor cantidad de operaciones, aunque con una participación menor (38,9\% en mayo de 2003 y $42,1 \%$ en mayo de 1999). El INDEC, señala que "la disminución de $8 \%$ en el número de operaciones en las bocas de más de $1.000 \mathrm{~m}^{2}$, fue captada en su totalidad por las bocas de hasta $500 \mathrm{~m}^{2 \prime}$.

También se observa en la tabla № 2 , que la variable "número de operaciones por $\mathrm{m}^{2}$ " es más adecuada, y refleja mejor la realidad intraformato, ya que relaciona la cantidad de operaciones con la superficie total y la de cada estrato; así, el "número de operaciones por $\mathrm{m}^{2}$ " se reduce a medida que crece el tamaño del formato. Para el mes de mayo de 2003 se verifica una disminución para todas las bocas de 10,8\% con respecto al mismo mes del año 1999; pero los supermercados más chicos (hasta $\left.500 \mathrm{~m}^{2}\right)$ pasaron a ubicar el primer lugar $\left(61,5\right.$ operaciones por $\left.\mathrm{m}^{2}\right)$ desplazando a los super de $501 \mathrm{a}$ $1.000 \mathrm{~m}^{2}$, que poseían este lugar en mayo de 1999. Aquí también son los hipermercados (más de $4.000 \mathrm{~m}^{2}$ ) los que sufrieron la mayor disminución porcentual en el "número de operaciones por $\mathrm{m}^{2 \text { " }} \mathrm{de}$ $27 \%$, seguido por las bocas de 501 a $1.000 \mathrm{~m}^{2}$ y las de 1.001 a $4.000 \mathrm{~m}^{2}(23,1 \%$ y $8 \%$ respectivamente), siendo solo los supermercados de menor tamaño, los que aumentaron el numero de operaciones por $\mathrm{m}^{2}$ en un $5,9 \%$.

Diferenciando entre grandes y medianas cadenas, el INDEC señala que para las primeras "el indicador número de operaciones por $\mathrm{m}^{2}$ muestra disminuciones tanto para el total de las bocas, como para cada estrato. En mayo de 2003 se verifica una disminución para el total de las bocas de $18,5 \%$ con respecto de mayo de 1999" (INDEC. 26/2/2004: 6). Por su parte para las cadenas medianas "el indicador número de operaciones por $\mathrm{m}^{2}$ refleja en mayo de 2003 un incremento de 
$10,4 \%$ con respecto de mayo de 1999 . Las bocas de hasta $500 \mathrm{~m}^{2}$ retuvieron la magnitud más elevada, y la de mayor aumento con respecto de mayo de 1999 (15,5\%)" (INDEC. 26/2/2004: 7).

Con respecto a las "ventas por operación", se verifican en la tabla $N^{\circ} 2$ aumentos en todos los tamaños de supermercados, observándose que éstas se incrementan con el tamaño de las bocas, siendo los hipermercados el estrato de mayor venta por operación en ambos períodos. Estos valores, se explican por la mayor variedad de artículos que se ofrecen en los hipermercados y supermercados más grandes, y por la menor asiduidad (frecuencia mensual o quincenal) de las visitas a estos grandes formatos comerciales por parte de los consumidores. Es decir en los formatos más grandes como supermercados grandes e hiper, las personas realizan compras de mayor volumen, porque incluyen en éstas todo tipo de productos (textiles, electrodomésticos, muebles, etc.), no solo alimenticios y/o de primera necesidad. Por su parte, el crecimiento en las ventas por operación de los formatos de supermercados más chicos, se deben a mayores ventas en productos alimenticios, limpieza, perfumería, entre otros.

Con respecto a las "ventas por $\mathrm{m}^{2 \text { ", }}$, se observa en la tabla $\mathrm{N}^{0} 1$, una disminución general para todos los formatos de supermercados del 6,6\%, tal como ya se había mencionado. En mayo de 2003, los supermercados de 1.001 a $4.000 \mathrm{~m}^{2}$ lideraron las ventas por $\mathrm{m}^{2}$, mientras que en 1999 ese lugar lo ocupaban supermercados de menor tamaño (de 501 a $1.000 \mathrm{~m}^{2}$ ). Analizando esta variable por

Mapa № 4: Supermercados Argentina. Variación en las "ventas por $\mathrm{m}^{2}$ "” (\$) según unidades espaciales

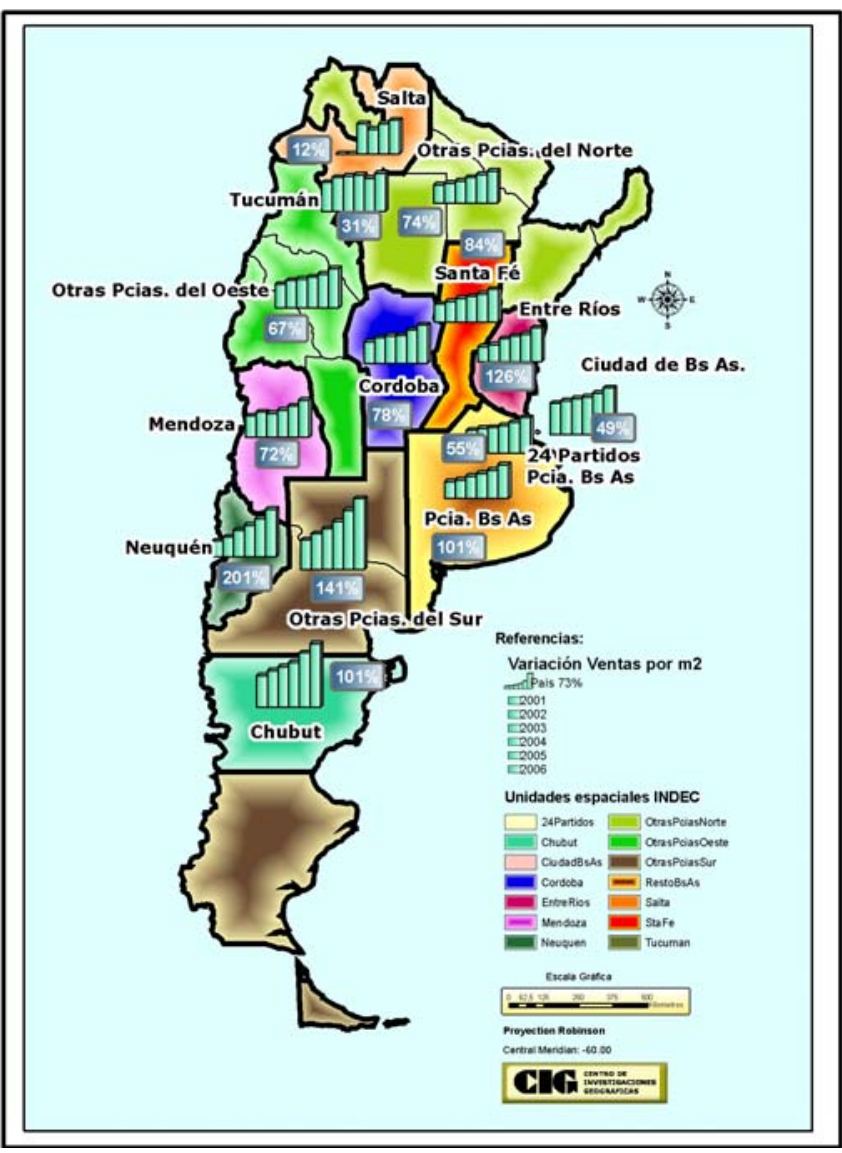

Fuente: elaboración personal sobre la base de INDEC "Encuesta de supermercados". 2/2001 a $1 / 2007$. estrato, se observa que el mayor aumento relativo en las ventas por $\mathrm{m}^{2}$, es en los supermercados más chicos (de hasta 500 $\mathrm{m}^{2}$ ), que representa un crecimiento del $14,6 \%$, mientras que la caída o disminución mayor, se da en los hipermercados con una variación del $17,1 \%$, entre los dos periodos analizados.

Existen diferencias en las "ventas por $\mathrm{m}^{2 \text { " }}$ entre las cadenas grandes y las medianas, ya que en las primeras las ventas por $\mathrm{m}^{2}$ disminuyeron $9,2 \%$ para el conjunto de las bocas, y en las segundas se incrementaron $5,1 \%$ para todas las bocas durante el período considerado (INDEC. 26/2/2004: 7).

En el mapa $\mathrm{N}^{\circ} 4$ se presentan las diferencias territoriales respecto a las ventas por $\mathrm{m}^{2}$, de los supermercados en Argentina, entre los años 2001 y 2006.

Se observan en el mapa, los gráficos de variación de las "ventas por $\mathrm{m}^{2 \text { " entre los }}$ años 2001 y 2006, para cada unidad espacial. Las provincias de Neuquén, Chubut, Entre Ríos, Buenos Aires, Córdoba, Santa Fe y "otras provincias del sur", presentan variaciones con valores por encima del promedio del país (73\%), debido básicamente a que la facturación por ventas de estos supermercados crecieron más, que las superficies de los mismos; por ejemplo Neuquén presentaba un decrecimiento en la superficie del área de ventas, (mapa $\mathrm{N}^{\circ}$ 2) pero el mayor crecimiento de las ventas (mapa $N^{\circ} 3$ ), en el periodo de años considerado. La provincia de Buenos

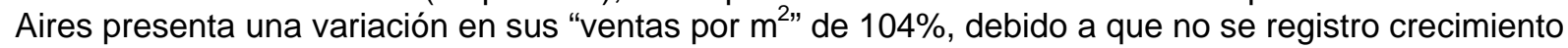
$(0 \%)$ en la superficie del área de ventas de los supermercados, pero sí crecieron las ventas (en miles de \$). 
Por otra parte, los partidos del GBA y la ciudad de Buenos Aires presentan un valor de variación por debajo del promedio, debido a que el crecimiento de las superficies y de las ventas de los supermercados, han sido bajos entre 2001 y 2006.

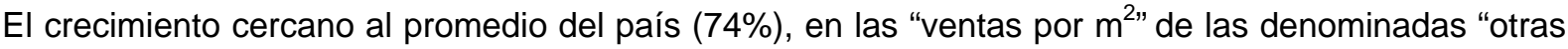
prov. del norte" se explica porque a pesar que las ventas de los supermercados no presentaron un importante crecimiento, la superficie de los mismos, cayeron con un valor de $-32 \%$, entre los años 2001 y 2006.

Existen además unidades espaciales en las que la variación resulta ser menor al promedio del país, como son Salta (12\%), Tucumán (31\%), "otras provincias del oeste" (67\%) y Mendoza (72\%); esta provincia presenta un valor muy cercano al promedio, debido a que el crecimiento es alto tanto en la variación de la superficie, como en las ventas de los supermercados.

Mapa № 5: Supermercados Argentina. "Ventas por $\mathrm{m}^{2}$ ", (\$) según unidades espaciales INDEC 2006.

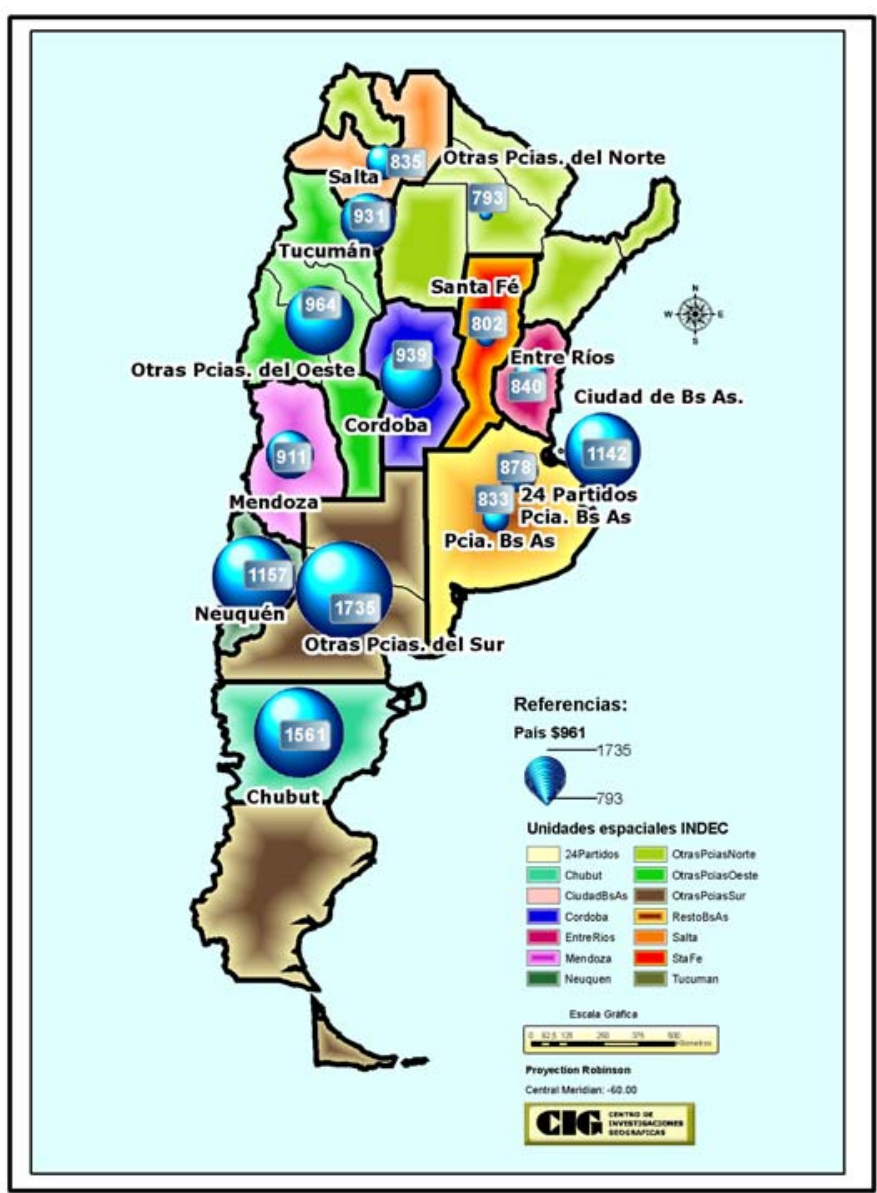

Fuente: elaboración personal sobre la base de INDEC

"Encuesta de supermercados". 2/2006 a 1/2007.
Para profundizar en las diferencias territoriales de los supermercados a partir de esta misma variable, se presentan a continuación dos mapas con las "ventas por m2" para cada una de las unidades espaciales: en el mapa $\mathrm{N}^{\circ} 5$, las correspondientes al año 2001 y en el mapa $\mathrm{N}^{\circ} 6$, las del año 2006.

Se observan en el mapa $N^{\circ} 5$, que las provincias de Chubut, la ciudad de Bs. As, "otras prov. del sur", Tucumán y el GBA, presentan "ventas por $\mathrm{m}^{2}$ ", con valores en $\$$ superiores al promedio del país; además, en las provincias de Neuquén, Entre Ríos, Buenos Aires, Santa Fe y "otras prov. del norte" los valores son muy bajos en el año 2001.

Ahora bien, en el mapa $N^{\circ} 6$, se pueden apreciar las diferencias territoriales en las "ventas por $\mathrm{m}^{20}$ de los supermercados en Argentina, para el año 2006.

Para el año 2006, se puede observar que las unidades espaciales que presentan valores por encima del promedio del país (\$961), poseen valores muy altos como son la provincia de Chubut (\$1561), ciudad de Buenos Aires (\$1142), "otras prov. del sur" (\$1735) y Neuquén (\$1157). Se puede afirmar que esta provincia poseía uno de los valores más bajos en el año 2001 (ver mapa № 5), pero como se ha analizado en el mapa № 4 el crecimiento de las "ventas por $\mathrm{m}^{2 "}$, presentó el mayor valor entre estos años considerados, por lo cual las "ventas por $\mathrm{m}^{2 \text { " del } a n ̃ o} 2006$, son una de las mas altas del país. 
Los valores más bajos en las "ventas por $\mathrm{m}^{2}$ " se registran en "otras prov. del Norte", Santa Fe, Buenos Aires, Salta y Entre Ríos, cuyos valores son muy bajos e inclusive presentan situaciones relativas peores que las del año 2001.

Mapa № 6: Supermercados Argentina. "Ventas por $\mathrm{m}^{2 "}$

(\$) según unidades espaciales INDEC 2001

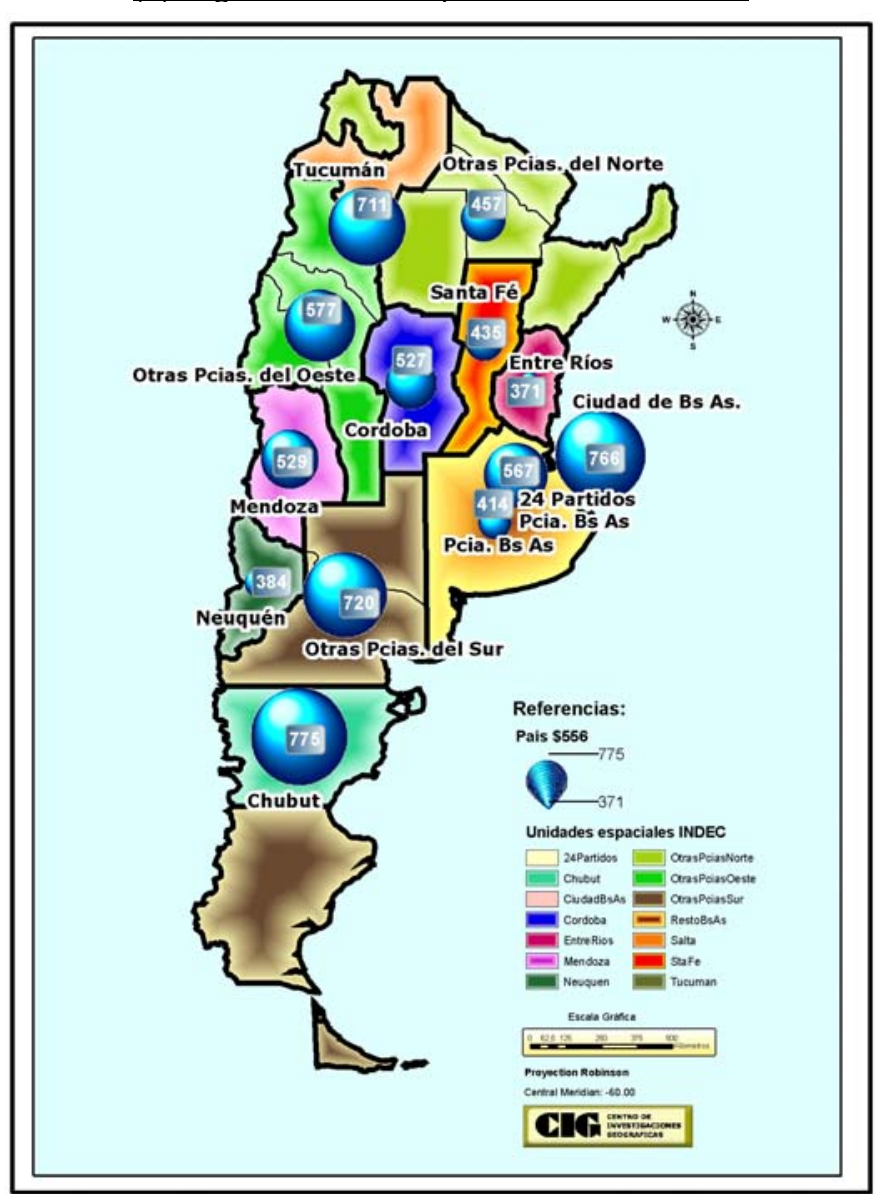

Fuente: elaboración personal sobre la base de INDEC

"Encuesta de supermercados". 2/2001 a 1/2007.
De esta manera y a través del análisis de estas variables seleccionadas de la Encuesta de Supermercados del INDEC, se puede afirmar que existen importantes diferencias territoriales en el país respecto a la presencia del sector supermercadista, con una importante concentración espacial, en primer lugar en el GBA y la ciudad de Buenos Aires, y en segundo lugar en las provincias de Bs. As, Córdoba y Mendoza.

En el análisis del período 2001-2006, se identifican importantes transformaciones en las provincias del interior del país, debido a que las cadenas de supermercadoslhipermercados más importantes se expanden territorialmente hacia estas, ya sea adquiriendo algunas cadenas como inaugurando nuevas bocas.

\section{Consideraciones Finales}

La globalización y la modernización del comercio minorista, de la mano de los grupos de distribución en Argentina, genera un espacio cada vez más fragmentado a partir del uso diferencial y jerárquico que estas empresas supermercadistas hacen de el conformándose así espacios luminosos y opacos hacia el interior de Argentina.

Así, las desigualdades y disparidades territoriales existentes históricamente en este país, son la configuración territorial sobre la cual actúan estos grupos, las cuales a partir del uso diferencial de este territorio profundizan y amplían la fragmentación territorial existente. De esta manera, a través del profundo análisis de variables que permitieron caracterizar a este sector, se demostró la concentración en el Gran Buenos Aires, Capital Federal, provincia de Buenos Aires y Córdoba, y además, el crecimiento a partir de fines de la década de los noventa dado por la política de estas empresas de expandirse hacia el interior del país, de algunas ciudades elegidas por el gran capital para ser un uso corporativo de esos territorios.

\section{Bibliografía}

COSTA, Augusto; KICILLOF, Axel y NAHÓN, Cecilia (2004). "Debate: Las consecuencias económicas de Sr. Lavagna. Dilemas de un país devaluado", en: Realidad Económica. IADE. № 203. Buenos Aires. 
CAC. CAMARA ARGENTINA DE COMERCIO. (5/2002) "Sondeo de actividad y opinión del comercio minorista" № 32. Observatorio de comercio y servicios PYMES del Departamento de Economía de la Cámara Argentina de Comercio. [En Línea]: http://www.cac.com.ar (17 de febrero de 2006)

CAME. CONFEDERACIÓN ARGENTINA DE LA MEDIANA EMPRESA. (1/1/2002). "Comunicado de prensa. Ventas de diciembre de 2001" [En Línea]: http://redcame.org.ar/comunicado.php3?id=94 $(9 / 12 / 2005)$

CAME. CONFEDERACIÓN ARGENTINA DE LA MEDIANA EMPRESA. (30/6/2002). "Comunicado de prensa. Ventas junio de 2002". [En Línea]: http://redcame.org.ar/comunicado.php3?id=138 $(9 / 12 / 2005)$.

CAME. CONFEDERACIÓN ARGENTINA DE LA MEDIANA EMPRESA. (4/12/2005). "Comunicado de prensa. Fuerte aumento de las ventas minoristas en noviembre (6,2\%)". [En Línea]: http://redcame.org.ar/comunicado.php3?id=433 (9/12/2005).

DI NUCCI, J y LAN, D. (2007a). "El "comercio tradicional" de la alimentación en Argentina. Redescubriendo espacios de la horizontalidad en un contexto de crisis", en: Revista Universitaria de Geografía. Departamento de Geografía y Turismo. Universidad Nacional del Sur. Vol. 16. 21 p. (en prensa).

DI NUCCI, J y LAN, D. (2007b). "Cambios en la distribución minorista de alimentos y bebidas en Argentina 2001-2003: hacia nuevas horizontalidades territoriales", en: Geograficando Revista de Estudios Geográficos. Depto. de Geografía. Facultad de Humanidades y Cs. De la Educación. UNLP. Argentina. № 3.15 p (en prensa).

INDEC. Encuesta De Supermercados. Relevamiento Anual Supermercados. Principales características de las bocas de expendio. Instituto Nacional de Estadísticas y Censos. Secretaría de Política Económica. Ministerio de Economía. República Argentina. 26/2/2004. 24 pág. [En línea]: http://www.indec.mecon.ar

MECON. Ministerio de Economía. Secretaría de Política Económica. Subsecretaria de programación económica. (12/2003) Monitoreo Sectorial. Informe sintético. [En línea]: www.mecon.gov.ar/peconomica/basehome/monitoreo sectorial.html (9/5/2006).

MECON. Ministerio de Economía. Secretaría de Política Económica. Subsecretaria de programación económica. (6/2003) Monitoreo Sectorial. Informe sintético. [En línea]: www.mecon.gov.ar/peconomica/basehome/monitoreo sectorial.html (9/5/2006).

MECON. Ministerio de Economía. Subsecretaría de Defensa del Consumidor. (10/2003). "Evolución comparada de la actividad del comercio minorista durante el 2003", en: Temas del Consumidor, № 65, pág. 79-84. [En línea]: http://www.mecon.gov.ar/secdef/revista (04/05/2004)

PÁGINA 12. (26/11/2004). "Supermercados para arriba, shoppings para abajo. Consumo con señales opuestas". [En línea]: http://www.pagina12.com.ar/diario/economia/2-44101-2004-11-26.html $(9 / 5 / 2006)$

SANTOS, Milton. (1996). O retorno do territorio. (SANTOS, Milton, SOUZA, Maria Adelia A de y SILVEIRA, Maria Laura. Org.). Território. Globalização e Fragmentação. $2^{\mathrm{a}}$ edição. São Paulo. Editora Hucitec. ANPUR. pág. 15- 20.

SEVARES, Julio (2002). “¿Por qué cayó la Argentina?”, en: Realidad Económica, IADE. Buenos Aires. № 188. pág. 6- 10.

SOUZA, M. A. de. (2003). Território Brasileiro. Usos y abusos. Ediçoes Territorial. Campinas, Março. Pág. 17- 26.

URIBE ORTEGA, Graciela. (1993). "La articulación entre lo global y lo local en los estudios de geografía humana". Quinto Encuentro de Geógrafos de América Latina. La Habana, Cuba, 9 pág. 